\title{
Editorial: Special Issue Catalysis by Precious Metals, Past and Future
}

\author{
Svetlana Ivanova *(D) and Marcela Martínez Tejada \\ Departamento de Química Inorgánica-e Instituto de Ciencia de Materiales de Sevilla, \\ Centro mixto Universidad de Sevilla-CSIC, 41092 Sevilla, Spain; leidy@us.es \\ * Correspondence: sivanova@us.es
}

Received: 19 December 2019; Accepted: 13 February 2020; Published: 19 February 2020

Precious metal catalysis is often synonymous with diversity and versatility. These metals successfully catalyze oxidation and hydrogenation due to their dissociative behavior towards hydrogen and oxygen, dehydrogenation, isomerization and aromatization, propylene production, etc. The precious metal catalysts, especially platinum-based catalysts, are involved in a variety of industrial processes. Examples include the $\mathrm{Pt}-\mathrm{Rh}$ gauze for nitric acid production, the $\mathrm{Ir}$ and $\mathrm{Ru}$ carbonyl complex for acetic acid production, the $\mathrm{Pt} / \mathrm{Al}_{2} \mathrm{O}_{3}$ catalyst for the cyclohexane and propylene production, and $\mathrm{Pd} / \mathrm{Al}_{2} \mathrm{O}_{3}$ catalysts for petrochemical hydropurification reactions etc. A quick search over the number of published articles in the last five years containing a combination of corresponding "metals" $(\mathrm{Pt}, \mathrm{Pd}$, $\mathrm{Ru}, \mathrm{Rh}$ and $\mathrm{Au}$ ) and "catalysts" as keywords indicates the importance of the Pt catalysts, but also the continuous increase in Pd and Au contribution (Figure 1).

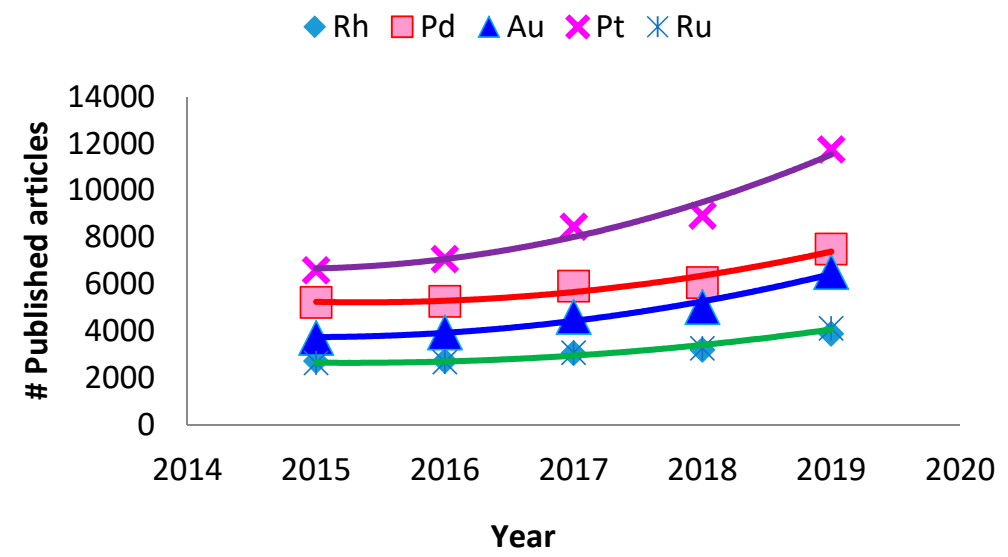

Figure 1. Number of published papers in the last 5 years, search directed on science direct page (www.sciencedirect.com) using combinations of simple keywords relating to corresponding metals $(\mathrm{Pt}, \mathrm{Pd}, \mathrm{Ru}, \mathrm{Rh}$ or $\mathrm{Au})$ and catalysts.

An important part of the Pt, Pd and Rh market includes the three-way catalyst (TWC catalyst), although the last research of the last 5 years reflects to a greater extent their participation in more fine chemistry reactions. The growth of the Pd catalyst market is reflected very well in this Special Issue by reports dealing with homogeneous and heterogeneous applications. Hobart, Jr. et al. [1] studied several palladium(II) bis-amino acid chelates for the oxidative coupling of phenylboronic acid with olefins. Despite having modest enantioselectivity, the Pd-complexes present a multiple cross coupling ability of the single substrate, providing a new horizon for the application of palladium organometallic complexes. The heterogeneous palladium catalysis are represented to a greater extent. González-Fernández et al. [2] described $\mathrm{Pd} / \mathrm{Al}_{2} \mathrm{O}_{3}$ catalyst activity in the gas phase hydrogenation of $\mathrm{C} 4$ alkynols. They found a special relationship between the hydrogenation rate and $\mathrm{C}-\mathrm{C}$ bond polarity. 
The rate increased following the order primary $<$ secondary $<$ tertiary alkynol. The secondary alkynol transformation rate increased due to the preferable ketone formation via double bond migration. Gao et al. [3] carefully designed Pd heterogeneous asymmetric catalyst for the hydrogenation of acetophenone. This strategy allowed the authors to obtain a highly dispersed high-loading catalyst, resulting in an important increase in the enantioselectivity. The ability of $\mathrm{Pd} /$ carbon nanotube catalysts to catalyze the dodecahydro-N-ethylcarbazo dehydrogenation reaction was studied by $\mathrm{M}$. Zhu et al. [4]. The catalyst revealed its potential as a stable and well performing catalyst for hydrogen production- $5.6 \mathrm{wt} . \%$ of hydrogen was maintained after five catalytic cycles. S. P. Samudrala and S. Bhattacharya [5] addressed the near future of the supported Pd catalysts, towards the sustainable synthesis of added value chemicals, specifically the direct hydrogenolysis of glycerol to 1-propanol the exemplified reaction. This study proposed a possible route to convert the biomass-derived glycerol (rest from the biodiesel industry) into useful chemicals. The optimization of catalyst and reaction parameters resulted in around $80 \%$ of total propanol yield.

On the other hand, A. Arevalo-Bastante et al. [6] compared the activity of the carbon-supported $\mathrm{Pd}$ catalysts to their $\mathrm{Pt}$ and $\mathrm{Rh}$ homologues in the hydrodechlorination of dichloromethane. The Pd catalyst in this case was taken over by Pt and Rh catalysts due to their higher stability upon sintering and their ability to maintain the active site unaltered during the treatment prior reaction and therefore. $X$. Auvray and A. Thuault [7] chose the $\mathrm{Pt} / \mathrm{Al}_{2} \mathrm{O}_{3}$ catalyst to study the effect of microwave pretreatment over precious metal dispersion. The microwave heating was compared to the conventional method of drying and calcination. It was found that microwave heating is only beneficial during drying but the conventional method was necessary to maintain acceptable metal dispersion. J. W. Jung et al. [8] also concentrated on the effect of reduction treatment over bimetallic Pt-Sn catalyst and its behavior in the reaction of propane dehydrogenation. Different Pt-Sn alloys were identified according to the reduction procedure. Well-dispersed $\mathrm{Pt}_{3} \mathrm{Sn}$ alloys were found to allow reaction acceleration together with coke migration and active sites preservation.

Ru was also represented in this Special Issue. M. Nishi et al. [9] designed a series of Cs-Ru catalysts supported on mesoporous carbon for ammonia synthesis. The catalytic results show an important dependence on Ru particle size and reduction behaviour, the latter being especially important to obtain the catalytically active phase metallic $\mathrm{Ru}$ with adjacent $\mathrm{CsOH}$ species. The ammonia synthesis utility of $\mathrm{Cs}$ - $\mathrm{Ru}$ catalysts was demonstrated for the first time, using $\mathrm{CO}_{2}$-free hydrogen from renewable energy with intermittent operation in Fukushima Renewable Energy Institute (FREA) of AIST, Japan.

The last group of publication involves different gold catalysts for photo and catalytic purposes. O. H. Laguna et al. [10] used $\mathrm{Au} / \mathrm{TiO}_{2}$ catalyst for photodegradation of phenol and $\mathrm{CO}$ oxidation. The gold catalysts prepared by photodeposition presented an important photoactivity due to the inhibited titania anatase-rutile transition. However, the prepared catalysts were less active in the gas phase oxidation of $\mathrm{CO}$ due to the sintering of the active phase. The importance of preserving gold nanoparticle size appears also to be a key factor in the study proposed by Chenouf et al. [11] where preformed gold colloids were stabilized by polymeric or solid-state protecting agents and immobilized on various ceria based oxides. The catalyst series was employed in two catalytic reactions, one in the gas phase and other in the liquid phase. In both reactions, the use of montmorillonite as a stabilizing agent resulted in very active catalysts due to different metal electronic state.

The review proposed by G. Ferreira Teixeira et al. [12] crowned the Special Issue and revised the role of precious metals in the perovskite photocatalytic and electrocatalytic processes. Silver and gold are the most employed metals to promote perovskites photoactivity, where the future points to the use of metal/perovskite hybrids for pollutants degradation or even for water splitting.

Let us finish as we start: the future of the precious metals is "shiny and resistant". Although judged expensive and potentially replaceable by transition metal catalysts, precious metal implementation in research and industry shows the opposite. Literally, every year new processes catalyzed by these metals appear, the best example being the important variety of biorefinery reactions or photocatalytic 
water splitting. Their versatility reflects their diversity and enlarges their current and future horizons of application.

Author Contributions: All authors contribute in a similar manner. All authors have read and agreed to the published version of the manuscript.

Funding: This research received no external funding.

Conflicts of Interest: The authors declare no conflict of interest.

\section{References}

1. Hobart, D.B., Jr;; Merola, J.S.; Rogers, H.M.; Sahgal, S.; Mitchell, J.; Florio, J.; Merola, J.W. Synthesis, Structure, and Catalytic Reactivity of Pd (II) Complexes of Proline and Proline Homologs. Catalysts 2019, 9, 515. [CrossRef]

2. González-Fernández, A.; Pischetola, C.; Cárdenas-Lizana, F. Gas Phase Catalytic Hydrogenation of C4 Alkynols over Pd/Al2O3. Catalysts 2019, 9, 924. [CrossRef]

3. Gao, X.; He, L.; Xu, J.; Chen, X.; He, H. Facile Synthesis of P25@ Pd Core-Shell Catalyst with Ultrathin Pd Shell and Improved Catalytic Performance in Heterogeneous Enantioselective Hydrogenation of Acetophenone. Catalysts 2019, 9, 513. [CrossRef]

4. Zhu, M.; Xu, L.; Du, L.; An, Y.; Wan, C. Palladium supported on carbon nanotubes as a high-performance catalyst for the dehydrogenation of dodecahydro-N-ethylcarbazole. Catalysts 2018, 8, 638. [CrossRef]

5. Samudrala, S.P.; Bhattacharya, S. Toward the sustainable synthesis of propanols from renewable glycerol over MoO3-Al2O3 supported palladium catalysts. Catalysts 2018, 8, 385. [CrossRef]

6. Arevalo-Bastante, A.; Martin-Martinez, M.; Álvarez-Montero, M.A.; Rodriguez, J.J.; Gómez-Sainero, L.M. Properties of Carbon-supported Precious Metals Catalysts under Reductive Treatment and Their Influence in the Hydrodechlorination of Dichloromethane. Catalysts 2018, 8, 664. [CrossRef]

7. Auvray, X.; Thuault, A. Effect of microwave drying, calcination and aging of $\mathrm{Pt} / \mathrm{Al} 2 \mathrm{O} 3$ on platinum dispersion. Catalysts 2018, 8, 348. [CrossRef]

8. Jung, J.W.; Kim, W.I.; Kim, J.R.; Oh, K.; Koh, H.L. Effect of Direct Reduction Treatment on Pt-Sn/Al2O3 Catalyst for Propane Dehydrogenation. Catalysts 2019, 9, 446. [CrossRef]

9. Nishi, M.; Chen, S.Y.; Takagi, H. Energy efficient and intermittently variable ammonia synthesis over mesoporous carbon-supported Cs-Ru nanocatalysts. Catalysts 2019, 9, 406. [CrossRef]

10. Laguna, O.H.; Murcia, J.J.; Rojas, H.; Jaramillo-Paez, C.; Navío, J.A.; Hidalgo, M.C. Differences in the Catalytic Behavior of Au-Metalized TiO2 Systems During Phenol Photo-Degradation and CO Oxidation. Catalysts 2019, 9, 331. [CrossRef]

11. Chenouf, M.; Megías-Sayago, C.; Ammari, F.; Ivanova, S.; Centeno, M.A.; Odriozola, J.A. Immobilization of stabilized gold nanoparticles on various ceria-based oxides: Influence of the protecting agent on the glucose oxidation reaction. Catalysts 2019, 9, 125. [CrossRef]

12. Teixeira, G.F.; Silva Junior, E.; Vilela, R.; Zaghete, M.A.; Colmati, F. Perovskite Structure Associated with Precious Metals: Influence on Heterogenous Catalytic Process. Catalysts 2019, 9, 721. [CrossRef]

(C) 2020 by the authors. Licensee MDPI, Basel, Switzerland. This article is an open access article distributed under the terms and conditions of the Creative Commons Attribution (CC BY) license (http://creativecommons.org/licenses/by/4.0/). 